\title{
A conceptual framework of clinical nursing care in intensive care ${ }^{1}$
}

\author{
Rafael Celestino da Silva² \\ Márcia de Assunção Ferreira ${ }^{3}$ \\ Thémistoklis Apostolidis ${ }^{4}$ \\ Marcos Antônio Gomes Brandão²
}

Objective: to propose a conceptual framework for clinical nursing care in intensive care. Method: descriptive and qualitative field research, carried out with 21 nurses from an intensive care unit of a federal public hospital. We conducted semi-structured interviews and thematic and lexical content analysis, supported by Alceste software. Results: the characteristics of clinical intensive care emerge from the specialized knowledge of the interaction, the work context, types of patients and nurses characteristic of the intensive care and care frameworks. Conclusion: the conceptual framework of the clinic's intensive care articulates elements characteristic of the dynamics of this scenario: objective elements regarding technology and attention to equipment and subjective elements related to human interaction, specific of nursing care, countering criticism based on dehumanization.

Descriptors: Nursing Care; Intensive Care Units; Biomedical Technology.

\footnotetext{
1 Paper extracted from doctoral dissertation "Different Styles of care in intensive therapy facing the technology: a contribution to the clinical in nursing care", presented to Escola de Enfermagem Anna Nery, Universidade Federal do Rio de Janeiro, Rio de Janeiro, RJ, Brazil. Supported by Conselho Nacional de Desenvolvimento Científico e Tecnológico (CNPq), Brazil, process \# 200554/2011-5.

2 PhD, Adjunct Professor, Escola de Enfermagem Anna Nery, Universidade Federal do Rio de Janeiro, Rio de Janeiro, RJ, Brazil.

3 PhD, Full Professor, Escola de Enfermagem Anna Nery, Universidade Federal do Rio de Janeiro, Rio de Janeiro, RJ, Brazil.

${ }^{4}$ PhD, Researcher, Laboratoire de Psychologie sociale, Aix-Marseille Université, Aix-en-Provence, France.
}

Corresponding Author:

Rafael Celestino da Silva

Universidade Federal do Rio de Janeiro. Escola de Enfermagem Anna Nery

Rua Afonso Cavalcanti, 275

Bairro: Cidade Nova

CEP: 20211-110, Rio de Janeiro, RJ, Brasil

E-mail: rafaenfer@yahoo.com.br
Copyright @ 2015 Revista Latino-Americana de Enfermagem This is an Open Access article distributed under the terms of the Creative Commons Attribution Non-Commercial License (CC BY-NC).

This license lets others distribute, remix, tweak, and build upon your work non-commercially, and although their new works must also acknowledge you and be non-commercial, they don't have to license their derivative works on the same terms. 


\section{Introduction}

The theme of clinical nursing is approached in different ways, ranging from the constitution of clinical knowledge to guide nursing practice ${ }^{(1)}$ to clinical education and its links with the production of care ${ }^{(2)}$ until reaching a concept of clinical nursing ${ }^{(3)}$. Brazilian Nursing publications on this theme address clinical research as support for care and also care itself as support for clinical research ${ }^{(4)}$. There is also concern about this issue in the field of psychiatric nursing in order to outline a specific clinic practice in that area(5).

Clinical nursing care occurs in a relationship between two subjects, transforming agents of the care act. This clinical practice is focused on care and includes the knowledge, needs and desires of the other(3). However, little has been discussed about clinical nursing practice related to the nurses' ways of taking care, leading to the need to investigate what nurses do or what needs to be done in a particular area of expertise to achieve care.

The incorporation of process technologies into the nurses' ways of acting towards the client has been proposed for clinical nursing care, which is the focus of this article. Thus, particularly in the elderly, the clinical practice is based on the valuation of culture and on the dialogical nature in the configuration of a shared care ${ }^{(6)}$. Internationally, clinical nursing is considered indefinite, because its knowledge is not private, the methods are difficult to identify and the instruments are registered in the medical field (7).

Clinical nursing practice in intensive care presents particularities of professional activities in this scenario, which constitute the dynamics of nursing care. One of them is technological objectivity in the professionals' actions, indicating different positions towards the intensive care nurses' ways of acting in view of the technologies ${ }^{(8-9)}$, making them the target of criticism.

Understanding this issue refers to the role of concepts, which correspond to ideas and perceptions of a phenomenon that guide the understanding of facts and propositions that articulate concepts in the attempt to explain a phenomenon. Concepts and proposals constitute the conceptual framework, a tool to identify the knowledge / action that constructs the scientific knowledge through reflection on the concepts that surround their work process ${ }^{(10)}$.

Identifying the elements that make up the conceptual framework of clinical nursing care in intensive care is critical because this offers better conditions to know how the practices in this sector are shaped and the meanings of the aspects that structure this framework and guide the actions. Thus, the central question in this research is: what elements make up the conceptual framework for clinical nursing care in intensive care? The objective is to propose a conceptual framework for clinical nursing care in intensive care.

\section{Method}

Descriptive and qualitative field research field based on the nursing meta-paradigm. This focuses on the interrelationship of four concepts that underlie the actions and identify the primary cores of interest of the profession, namely: nursing - science and art of caring for the individual to reach an optimal level of health; human being - individual wholeness with qualities and physical, intellectual, emotional, social and spiritual potential; health - physical, mental and social wellbeing, which results from the balance of the organism, disease being an imbalance that threatens the life and safety and environment - health / disease process that derives from the subject's relationship with the environment ${ }^{(10)}$.

The research field was the Intensive Care Unit (ICU) of a federal hospital in the city of Rio de Janeiro, where 24 nurses work. Twenty-one participated, 17 women and four men who met the inclusion criteria: work directly in care, in the study period, between January and June 2011. Three of them were excluded (on leave and managers). Most nurses had up to ten years of training $(61.9 \%) ; 52.4 \%$ were under 35 years of age; $57.1 \%$ had two jobs, worked in the day shift and were intensive care specialists; $66.7 \%$ chose to work in the ICU and $71 \%$ had up to 5 years of experience in this ICU.

The data was produced through individual interviews, applying a semi-structured script with open questions about the daily practice in the ICU, care style, use of technologies among others. We conducted a pilot test of the instrument with ICU nurses from another institution to adapt the questions and check its functionality to reach the proposed goal. The interviews were held in the field of study, in the afternoon, and took an average one hour and thirty minutes, being electronically recorded.

The analysis was undertaken using Alceste 2010 software, which is a computerized text analysis method. The text is divided into Elementary Context Units (ECU) that distribute the vocabulary into lexical classes. The 
profile of each class corresponds to the words most associated with those classes, and this association is calculated using chi-squared $\left(\mathrm{chi}^{2}\right)$.

Alceste produced a report with $58 \%$ of text use and six lexical classes. The group of six classes and the relationship between them were analyzed, specifically exploring the class lexicons that could portray the discussion of the conceptual framework. The contents of the classes, as well as their quantitative use, are as follows: Class 1 dealt with the features of the technology $(10.4 \%)$, class 2 with the organizational elements of the care styles $(10 \%)$, class 3 with the daily care routine (18 1\%), class 4 with the external structural factors of care $(19.0 \%)$, class 5 with the practice of care using technology $(11.6 \%)$ and Class 6 with the patient's characteristics as an indicator of work at the ICU $(30.9 \%)$.

The thematic content analysis technique was also applied to the interviews, by tracing the occurrence and co-occurrence of themes in the testimonies, with the application of the procedure per mile. This technique was complementary to capture thematic contents that expressively or latently translated the elements of the conceptual framework that were not identified in Alceste. The cores of meaning elaborated were contrasted with the lexical classes produced in Alceste, enriching examples of illustrative contents of the axes of analysis in the light of the nursing meta-paradigm.

In view of this triangulation of the analysis techniques and the apprehension of the nursing meta-paradigm, the characterization of the elements involved in the conceptual framework was organized in four areas: nursing - science and art; environment; human being and human being and health. According to these axes, the ECUs generated in Alceste and the Registration Units (RU) taken from the content analysis, illustrate the descriptive presentation of the elements that make up the conceptual framework of nursing care in intensive care.

The study received approval from the Institutional Review Board of the hospital - field of study (Protocol 35/10). The participation of nurses was voluntary and they signed the Informed Consent Form (ICF).

\section{Results}

These study results will be presented according to the ECUs and RUs in the thematic axes, according to the reference framework of the nursing metaparadigm.

\section{Nursing - science and art}

Specialized knowledge: instruments nurses use to develop their actions in the intensive care unit. Guides the application of technologies in care and clinical management of the client, outlining a profile for work in this sector.

The words of Class 2, such as seek (chi2: 78.9), knowledge (chi²: 72.5) want (chi2: 32.5) illustrate this knowledge, as well as the words present in class 5 . The appropriation of knowledge inherent in work at the ICU is a requirement for the performance of the actions, especially in view of advanced technologies. This, in turn, depends on individual efforts to search for this knowledge, which will be reflected in practice through a specific care style, distinguishing the care forms for the client.

First you have to be willing to learn, but after that passes, after you have mastered it, you turn into a mere task performer, then you have to go further, but it depends on each person whether you want to look for more or not (ECU3405, nurse 20).

You have to detect the problem and verify the causes of that, but you need to know the clinical practice for that, and you have to be close to the patient, have to be looking at him and be at his side (ECU1912, nurse 13).

Despite the profile, the mastery of theoretical and practical expertise is by itself an obligation of the professional who chooses to act in this sector. As a result, a set of personal and professional characteristics is organized to give support to this requisite. In Class 2, the words fit (chi2: 44.8) and profile (chi2: 39.7) show that the adaptation and profile encompass the updating of the knowledge to manage the care instruments.

When you make a selection, you need to do it according to the profile of each, because without a profile you really will not adapt, you don't adapt (ECU3336/3329, nurse 20).

Being agile in certain situations is not just about agility, you need to know how to handle things, deal with things (ECU1435, nurse 9).

Care activities: comprise a set of management and direct client care actions, comprising technical procedures, assessment and clinical intervention, records, medication support, dialogue, technology use.

Bureaucratic medication-related activities involve planning the medication administration and this daily concern in care appears in class 3 through the words medication (chi2:201.7), time (chi2:97), prescription (chi2:74.1). 
There's the monitoring, the prescription has already been divided, you just have to take it, you tke the medication so as not to delay the time, for the technician to administer the medication (ECU1544, nurse 10).

What is a priority for the system today I need to comply with, because if I don't loose almost the entire morning taking the medication, the morning medication will not be done (ECU755, nurse 5).

The execution of the bath ( $\left.\mathrm{chi}^{2}: 89.9\right)$, dressing $\left(\mathrm{chi}^{2}: 88.1\right)$ and line passage (chi²:39.1) are examples of direct care activities that also show the nurse's interest in procedural care in her daily work.

We usually enter during the baths with the technicians, do all the invasive procedures, do the clinical test, we take the medication, we are talking about care (ECU3032, nurse 19).

When it's time for turning (during the bath) I already stay there, apply all the dressings needed, examine, I already get out of there knowing what to do, for you to go there earlier just to hold, cast water (ECU846, nurse 6).

Interaction: used by nurses during client care actions to apprehend their needs and conduct interventions. When interacting with the patient, the nurse applies clinical references and also works based on intersubjectivity. If the interaction is used to instruct (protocol-based) care, it is only based on clinicalhemodynamic information the equipment produces; if you have a constructive intention, negotiation and co-participation produces subjectivities that meet the principles of the science and art of nursing(11).

This theme of interaction with the client in the intensive care emerged from the thematic content analysis with $17 \mathrm{RU}$. The instructive interaction is proven when the nurse, in view of the ICU setting, classifies the patient based on his level of severity, focusing on the objective data of the patient with the highest level. The interaction with the client is clinical, ignoring subjective demands, mainly of the less severe patients.

There are people who are more focused on the respirator, on the monitor, in short, on monitoring, on the machine in general (...) therefore, the people say that they don't like it, because they prefer a sedated patient, who does not interact, and comatose, because there will be no exchange with the patient and the care will only be based on monitoring (RU, Nurse 8).

Administrative and care management is a factor that contributes to instructive interaction, as compliance with the routines, mainly the bureaucratic routines, distances the nurse from the client and only visits him punctually.

The shift turns into this agitated chaos, procedures happening at the same time, when you finish one routine the next time is already there, for you to continue the work, then it bothers me that I can't even see the patient's face. I don't know if it's the daily work, what ends up happening is that the nurse is more distanced from the patient and closer to the machine (...) there's actually little time left to go to the beds (RU, Nurse 4).

In the constructive condition there is engagement with the customer in order to understand the experience of illness in the context of their lives. What matters is clinical information, but also the dialogue with him and his family, so as to fully know them.

I think there are people who do care about this subjective aspect. There are people who get involved with the patient, but deal with it in a much more relaxed manner (RU, Nurse. 8).

In short, Nursing at the ICU translates into the implementation of care activities that require the mastery of specialized knowledge, guided by the interaction mediated by clinicians and inter-subjective aspects, which express the science and art of the profession.

\section{Environment}

Work context in intensive care: scenario in which the nursing work is processed, composed of environmental, structural and institutional particularities that interfere in care, through the production of positive and negative feelings based on the experience lived.

The structure of the institution is understood as a variable external to care, but present in the context it is accomplished in, which affects its quality. That is so because a small number of employees or the lack of material produces inappropriate work conditions that provoke a burden in the professional, influencing the care, situations alerted on in class 4 in the terms structure (chi2:70.2), service (chi2:51.1), hospital (chi2:41.5).

There are external factors, other variables that will interfere in care, and I think that's my main concern today, that we are working in the public service with a deficient structure (ECU 3694, nurse 21).

Sometimes the fatigue is strong, and that ends up being clear not only in the conversations, but even in the figure of the nruse, the questions beyond care end up interfering in that fatigue (ECU3769, nurse 21).

The work relations among the professionals in the team are another aspect of class 4 that exemplify this external influence. The words nurse (chi2:157.8), professionals (chi²:96), interaction (chi $\left.{ }^{2}: 40.3\right)$, relationship (chi2:32.4), physician (chi²-36.6) reveal asymmetries and conflicts and their relations with the care delivered.

In general, the relationship is good, most of the people are in there most of the time: physiotherapists, physicians and nurses. As regards the people from outside, from diet therapy, 
we don't have a relationship, we say what is basic, sometimes they say things we don't agree with (ECU2753, nurse 17).

Now I think that we are unable to have a good interaction there, it's not interaction, I think that the physicians, the intensive care professionals there are not intensive care professionals (ECU3099, nurse 19).

Technology in intensive care: instrument to enhance the client's recovery applied by the nurses, based on objective data the equipment produces. Its use is mediated by professional values and knowledge.

Its care aspect is expressed in class 1 when it is used to assess the client, identify, direct and foresee clinical alterations. The words technology (chi2:275.74), care (chi2:116.9) and technological (chi2:103) appoint its pragmatic use in care.

Technology favors a better assessment, grants you further safety in care and permits questions further ahead, more concrete than when technology does not work in your favor (ECU 2210, nurse 15).

The achievement of this pragmatic use implies proximity to the patient. The word 'question' $\left(c^{2}: 83.1\right)$ indicates that the use of technology appeals to the professional values, mainly human dignity, in the solution of the client's comprehensive needs.

Nursing care cannot be left aside, in the sense that the technology issue prevails to the detriment of that question of being close to the patient, taking care (ECU2211, nurse 15).

The organizational side of work means that the nurse uses it to manage the client's clinical responses at a distance while she accomplishes her administrative activities. This function of the technology, marked in class 1 by the words administrative (chi²:96.8) and distant (chi2:66.7) shows that the nurse focuses on administrative activities as that is easier.

This thing with technology in care is much more divided with administrative issues (...) today the nurse has much more administrative activities to do and then he prioritizes that (ECU2273/2245, nurse 15).

Lately, as the nurse is more distant from the bedside in her work, leaving the care practice for the nursing technician, the procedure has to do more without the nurse's coherent observation, although many professionals do it for commodity, for facility's sake (ECU2218, nurse 15).

The environment of the ICU is technological, has its own internal dynamics in which the equipment influences the type of care delivered to critical patients. The changes in this environment interfere in the work developed there.

\section{Human being}

Intensive care patient: singular human being with characteristics that define him/her as specific to this scenario, requires intensive monitoring of the health/ disease continuum through advanced resources and demands technical and sensitive care.

The conceptions linked to the patient are present in class 6 , mainly through the words speak (chi2:76.3), patient (chi2:67.8), awake (chi2:53.1), sedated (chi2:41.2) and lucid (chi²:39.6). It is acknowledged that the nurse's work at the ICU incites him/her to experience feelings based on the clients' communicative condition.

When the client wakes up and talks after a critical phase, this indicates the effects of nurses' work, who feel gratified, but nevertheless prefer the sedated client, in view of the lesser occupation as, when awake, there are countless requests and emotional demands. This reveals the typical image of the ideal ICU patient: severe/sedated/intubated/recoverable.

That's the thing with the evolution I've already mentioned, watching the extremely severe patient get out of here well, laughing, talking, that's really gratifying for me, I can't imagine myself working any other way (ECU2944, nurse 18).

There are people, like I've heard here: ah, don't put me with a patient who's awake, I prefer sedated patients, don't put me with that patient, because that patient asks (ECU1227, nurse 8).

Intensive care nurse: professional with formal, scientific and specialized knowledge, among other attributes, which enables him/her to deliver care to people in critical conditions with the help of technologies. Combines technique and sensitive with a view to the patient's recovery.

The personal/professional attributes that compose the figure of the intensive care nurse stand out in class 2, including aspects related to the client and the equipment, such as liking, agility, stability, responsibility, management/interpretation, as identified in the following ECUs.

Being emotionally stable to work there, knowing how to work as a team (ECU1435, nurse 9).

I think you need respect and responsibility, commitment, knowledge, human being, humanization, treating the patient as a being in all aspects and companionship (ECU2553, nurse 16).

In summary, the human beings are constantly interrelated. The ICU nurse performs specialized work and has typical attributes to take care of patients with 
critical characteristics that arouse affections that guide their care mode.

\section{Health}

Care frameworks: principles based on theoreticalphilosophical bases in health and nurse that guide care lines in intensive care.

The existence of a biomedical framework based on a rational health concept Is observed in excerpts of ECUs in class 3 , when the nurses discuss the execution of automated actions to attend to biological needs, which occur in a way that is disjointed from the other dimensions of client care.

I gave a bath, do my patients' evolution, I don't do anything else, negative, it shouldn't be like that, things could be programmed, although it depends on the prescription, you should be doing it together (ECU2529, nurse 16).

All of this creates great anguish, our way of doing things, which we sometimes do automatically, give some medication here, that was where I installed the access (ECU733, nurse 5).

Class 5 also contains the frameworks aligned with the environment and the profession, based on human dignity, as it shows the team's efforts to recover the critical patient, applying intensive care and advanced therapeutics.

The patient having a fever, why? Tachycardic, hypertensive, increase the noradrenaline or reduce it? You need to be assessing, I need to take initiative, those things serve to intervene (ECU1634, nurse 11).

The health framework is understood as: state of equilibrium, achieved through the application of advanced therapeutic care focused on the biological recovery of critical patients, and expressive care focused on the integral dimension of the human being.

\section{Discussion}

Nursing, understood as the science and art of helping involves, on the one hand, theoretical knowledge with its principles and organizing concepts, and on the other hand the practical knowledge deriving from experience. At the ICU, the science and art are materialized in specialized knowledge, whose importance is marked in the productions in this area(12-13).

A study involving professionals from a mobile ICU about intensive care to people at risk of death evidenced knowledge as one of the parts of the central core of social representations, constituting the essence of intensive care ${ }^{(14)}$. Other authors defend the existence of technological care at the ICU, in which the nurse's application of a higher knowledge level focuses his/her attention on the search for objective and subjective data coming from the client, as well as objective data the equipment produces ${ }^{(15)}$

At the OCI, the knowledge mastery is evidenced and defines the nurse's care style, mainly through the requirements related to the equipment management. This peculiarity gains international repercussion through the discussion on the need to use the nurse's clinical expertise in the prevention of incidents involving technologies. These incidents demonstrate the influence of technical knowledge on the promotion of safe equipment use at the ICU, arousing the nurse's active participation in this process $^{(13)}$.

As to the art of nursing, the intersubjective relation mediated by interaction has been the focus of research interests due to the fact that the different dimensions involved in intensive care are not understood as a complex and integrated whole. In that sense, concerns emerge in the attempt to rescue the respect for the aspect that support the expression of this art, like the interpersonal relationships and interactions for example(8).

Some professionals prefer "quiet" patients and relatives who do not bother or do not demand involvement ${ }^{(8)}$ and, in line with this result, Nurse 8 's testimony highlights the predominance of technologybased objective clinical frameworks; guiding the nurse's interaction with the client.

The encouragement of effective communication among the stakeholders of care is a current reality, in the sense that errors do not cause harm to the patients, as it is estimated that many of the errors and adverse events occur due to communication problems ${ }^{(16)}$. That reveals the importance of understanding the complexity of care and the dialogical relation as the base for the intersubjective interaction and experience, arousing sensitive perception in the other ${ }^{(8)}$.

The environment in health is part of a system where the individuals who constitute the care network are located in, who interact mutually and with the environment, influencing one another. Different approaches to the influences of the context in care are found in the literature, like occupational health for example, in view of the contemporary configurations of work, in which rhythm, hour load and strict control are even more enhanced characteristics at the ICUs.

In the data about the risk factors for the health of ICU workers, the work organization stands out, classified as severe, as well as the socioprofessional relationships, 
assessed as moderate to critical risk, in view of the professional disputes ${ }^{(17)}$.

Although the analysis axis on the context does not specifically refer to occupational health, it indicates that dealing with structural and environmental contingencies on a daily base produces negative experiences that can compromise the health and influence the care styles, showing the relations between professional activity and the context in which care takes place.

The equipment-related technologies produce representations that guide the ways in which the nurses deal with them. International studies present ideas that associate the subject-machine with an interdependent undissociable unit, in a symbiotic relationship, or that indicate that the technology modifies the dynamics between nurse and patient, as the language it communicates and which the nurses translate puts them in a position distant from the clients $^{(18-19)}$.

These aspects, as opposed to the data, mainly when the subjects attribute functions to the technology, reveal the central place of the technology in this clinical practice, that is, the client care practice at the ICU is organized based on the meaning the professional attributes to this technology.

The concept of human being around which one of the analysis categories was organized defines the individuals engaged in the actions and was in line with the concept of other productions, as this being lives and relates with other peers, being historical, social, singular, integrated, comprising a physical dimension and others that comprise the meanings, desires, thoughts, memories ${ }^{(8)}$.

Concerning the nurse's communication difficulties with the client, his/her characteristics are revealed, which are: clients who do not communicative and have limited interactive demands ${ }^{(8)}$. These characteristics rest on the imaginary dimension of intensive care, that is, a critical/severe patient who uses advanced equipment and requires specialized care in emergency situations: taking care of a severe patient, with technologies and perceiving his/her recovery until the time when (s)he is able to talk and will be discharged ${ }^{(20)}$.

In the analysis of the elements of the clinic, this type-figure Nurse 3 announced demands interventions with a view to reorganizing the meanings that construct this representation and that implies excluding practices. As to the profile, the discussions are focused on an adequacy that attends to the peculiarities of this sector. Hence, personal and technical qualities are sought that guarantee clinical competency in the management of technologies and problems with the client, based on knowledge, skills and judgment( ${ }^{(15)}$.

Finally, the theoretical framework of nursing practice brings a care philosophy in which the health concept depends on man's harmony with nature, in a state of balance among different components, mind, body and environment. Nevertheless, this holistic framework is not always applied at the ICU, like in the case of the nurses who refer to their care activities as simplified practices based on biological needs.

Hence, the currents that guide them are discussed, aiming to incorporate the reference framework of integrality in client care, apprehending the complexity in a multidimensional form; thus granting conditions to globally attend to the human being(8).

The articulation of the constitutive elements of clinical nursing care in the intensive care permits structuring its conceptual framework which, in turn, explains this clinical practice and serves as a framework. The publications contain definitions of clinical care like, for example, the field of biopsychosocial knowledge and practices that interact in a circular manner and influence the professionals in their ways of acting(4).

In nursing, the authors defend the definition of a clinical practice characteristic of this area, as a medical clinical plan was appropriated, taking the role of organizer of spaces and bodies, objectifying the subjects and their needs. Therefore, clinical nursing practice needs to be reinvented based on the valuation of the other person's knowledge in parallel with the scientific knowledge, the use of listening tools in which the word is the raw material, care is the core objective, disease is part of the experience of the subject's existence(3).

Despite the limitation of being developed with a single team from a specific hospital area, the study indicate that clinical nursing care in nursing care is based on the interaction among human beings, based on which, modulated by specialized knowledge and technology, the nurse performs care activities focused on critical patients, which express the science and art of care and reflect the characteristics of the environment related to the work and the health care frameworks, serving as the conceptual design.

The contribution of this study can be evidenced by the proposal of a conceptual design in which the human beings and the environment influence one another and a change in one influences the other. Interventions in these systems need to be devised to improve the quality of care. It is presupposed 
that intervening in the work context would directly influence the interface between nurse and critical patient; modifying the health care frameworks would interfere in the expression of the science and art of nursing, enhancing the quality of the actions; investing in the nurse's specialized knowledge would influence the execution of the care activities, especially in the expression of nursing science.

\section{Conclusion}

The conceptual framework for clinical nursing care in intensive care consists of elements that are organized around specialized knowledge, care activities, technology, interaction, work context, type of patient and nurse characteristic of intensive care and the care frameworks. These elements are characteristic of the dynamics in this scenario: objective characteristics related to the technologies and subjective characteristics related to human interaction.

This conceptual design indicates actions aimed at: the formulation of public policies regarding the number of employees, intensive care nursing education in the light of the professional profile and reference frameworks of integrality, at the level of direct care for the client in the change of the care model and in the valuation of the subjects as co-participants in view of the National Humanization Policy, with strategies based on dialogue and negotiation.

\section{References}

1. Matumoto S, Fortuna CM, Kawata LS, Mishima SM, Pereira MJB. Nurses' Clinical Practice in Primary Care: a Process Under Construction. Rev. Latino-Am. Enfermagem. 2011;19(1):123-30.

2. Vieira NA, Silveira LC, Franco TB. A formação clínica e a produção do cuidado em saúde e na enfermagem. Trab Educ Saúde. 2011;9(1):9-24.

3. Oliveira DC, Vidal CRPM, Silveira LC, Silva LMS. O processo de trabalho e a clínica na enfermagem: pensando novas possibilidades. Rev Enferm UERJ. 2009;17(4):521-6.

4. Sousa LD, Lunardi Filho WD, Lunardi VL, Santos SSC, Santos CP. A produção científica de enfermagem acerca da clínica: uma revisão integrativa. Rev Esc Enferm USP. 2011;45(2): 495-500.

5. Moreira LHO, Loyola CMD. Internação involuntária: as implicações para a clínica da enfermagem psiquiátrica. Rev Esc Enferm USP. 2011;45(3):692-9
6. Teixeira MLO, Ferreira MA. Cuidado compartilhado: uma perspectiva de cuidar do idoso fundamentada na educação em saúde. Texto Contexto Enferm. 2009;18(4):750-8.

7. Etienne MS. Éléments d'une clinique en soins. RSI. 2005; (82):11-5.

8. Backes MTS, Backes DS, Erdmann AL, Büscher A. O cuidado intensivo oferecido ao paciente no ambiente de Unidade de Terapia Intensiva. Esc Anna Nery. 2012;16(4):689-96.

9. Browne M, Cook P. Inappropriate trust in technology: implications for critical care nurses. Nurs Crit Care. 2011;16(2):92-8.

10. Taube SAM, Zagonel IPS, Meier MJ. Um marco conceitual ao trabalho da enfermagem na central de material e esterilização. Cogitare Enferm. 2005;10(2):76-83.

11. Ferreira MA, Alvim NAT, Teixeira MLO, Veloso RC. Saberes de adolescentes: estilo de vida e cuidado à saúde. Texto Contexto Enferm. 2007;16(2):217-24.

12. Kendall-Gallagher D, Blegen MA. Competence and certification of registered nurses and safety of patients in Intensive Care Units. Am J Crit Care. 2009;18(2):106-14.

13. Mattox E. Medical Devices and Patient Safety. Crit Care Nurse. 2012;32(4):60-8.

14. Nascimento KC, Tosoli AM, Erdmann AL. A estrutura representacional do cuidado intensivo para profissionais de Unidade de Terapia Intensiva móvel. Rev Esc Enferm USP.

2013;47(1):176-84.

15. Silva RC, Ferreira MA. Representações sociais dos enfermeiros sobre a tecnologia no ambiente da terapia intensiva. Texto Contexto Enferm. 2009;18(3):489-97.

16. Abraham J, Kannampallil T, Patel B, Almoosa K, Patel VL. Ensuring patient safety in care transitions: an empirical evaluation of a Handoff Intervention Tool. AMIA Annu Symp Proc. 2012:17-26.

17. Campos JF, David HSL.Work Context Assessment in intensive therapy units from the perspective of work psychodynamics. Rev EsC Enferm USP. 2011;45(2):359-64.

18. Brangier É, Hammes-Adelé S, Bastien J-MC. Analyse critique des approches de l'acceptation des technologies: de I'utilisabilité à la symbiose humain-technologieorganisation. Revue européenne de psychologie appliquée. 2010;60:129-46.

19. O'Keefe-McCarthy S. Technologically mediated nursing care: the impact on moral agency. Nurs Ethics. 2009;16(6):786-96. 
20. Martins JT, Robazzi MLCC, Garanhani ML. Sentimentos de prazer entre enfermeiros de unidades de terapia intensiva. Cienc Enferm. 2009;15(3):45-53. 